Afrika Focus, Vol. 7, Nr. 1, 1991, pp 15-48

\title{
THE USE OF SPOT-HRV DATA FOR THE MAPPING OF THE LAND COVER (APPLIED UPON EAST-MONO, CENTRAL TOGO)
}

\author{
Beata Maria DE VLIEGHER \\ State University Ghent \\ Laboratory for Regional Geography and Landscape Science \\ Krijgslaan 281 (S8-A1) \\ 9000 GENT
}

CURRENT RESEARCH: remote sensing, soil degradation mapping, Mediterranean area.

\section{SUMMARY}

The mapping of the land use in a tropical wet and dry area (East-Mono, Central Togo) is made using remote sensing data, recorded by the satellite SPOT. The negative, multispectral image data set has been transferred into positives by photographical means and afterwards enhanced using the diazo technique. The combination of the different diazo coloured images resulted in a false colour composite, being the basic document for the visual image interpretation. The image analysis, based upon differences in colour and texture, resulted in a photomorphic unit map. The use of a decision tree including the various image characteristics allowed the conversion of the photomorphic unit map into a land cover map. For this, six main land cover types could be differentiated resulting in 16 different classes of the final map.

KEY WORDS : Remote sensing, SPOT, Multispectral view, Visual image interpretation, Mapping, Vegetation, Land use, Togo. 


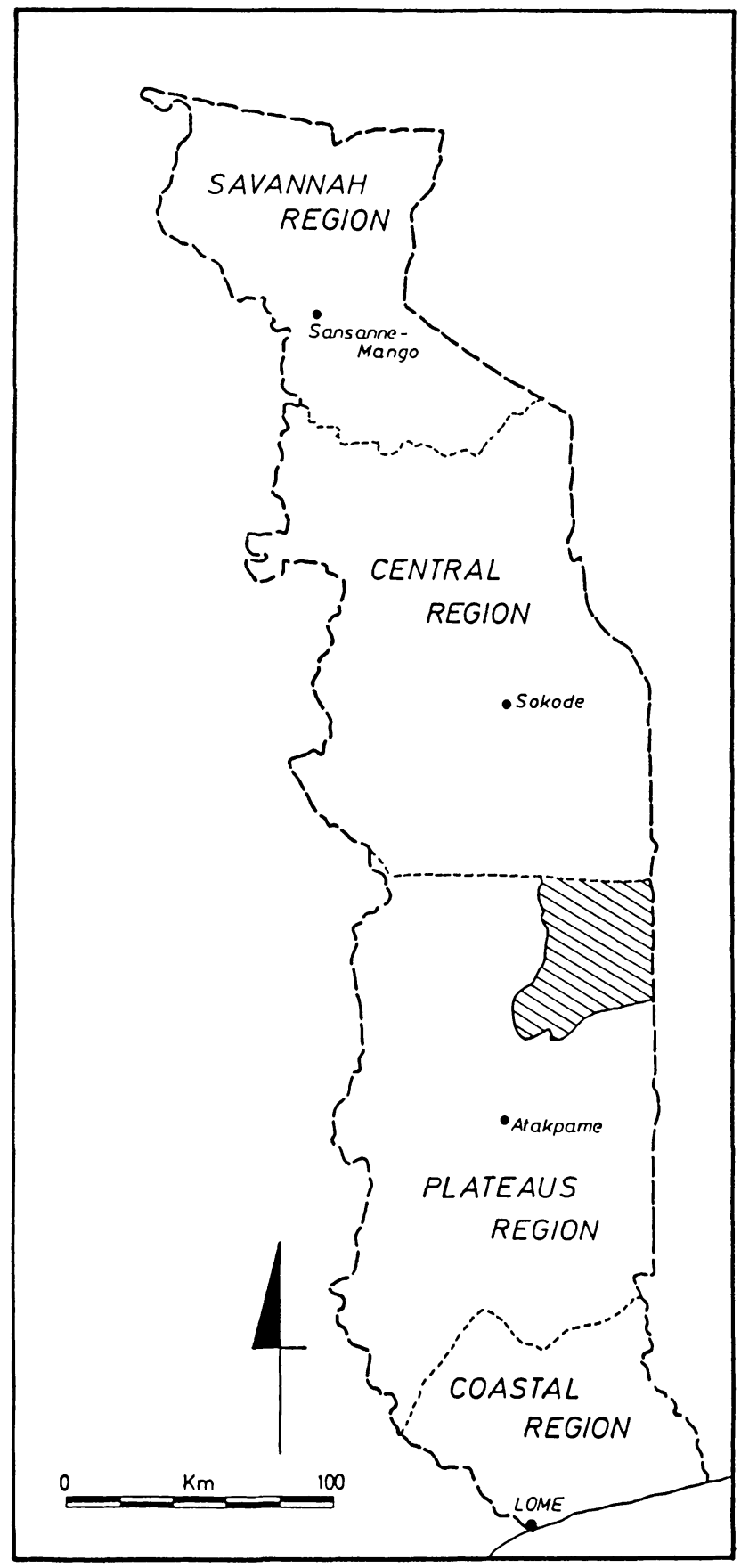

Study area

Figure 1 - Localization of the study region 


\section{INTRODUCTION}

This paper summarizes the methodology and the results of a study performed by order of BELGROMA, Brussels and is part of the project "Etude de factibilite du projet de développement rural intégré de l'Est Mono - République de Togo". The aim of the study was to map and to quantify, by means of remote sensing data, the land cover, including natural vegetation as well as land use (crop land, fallow land and plantations).

\section{DESCRIPTION OF THE STUDY AREA}

The study has been applied upon the area of East Mono situated in the plateaux region, Central Togo (Figure 1). The study area extends between $8^{\circ} 22-7^{\circ} 48^{\prime} \mathrm{N}$ and $1^{\circ} 07^{\prime}-1^{\circ} 38^{\prime} \mathrm{E}$. The area is limited by the river Mono and the Central region to the west, the river Mono and its tributaries to the south, Benin to the east and the Central region to the north. It has an extend of about 250,000 ha.

With the exception of the Togo mountains extending from the SSW to the NNE, the altitude never exceeds $500 \mathrm{~m}$ (Figure 2). The mountains are divided by deep valleys into plateaux.

Mount Agou, the culminating point with an altitude of $988 \mathrm{~m}$, is located in the very southern part of the mountain range. In general, the altitude of the study area varies between 200 and $300 \mathrm{~m}$. The valleys of the rivers Mono and Ogou are cut into the plateau to altitudes below $200 \mathrm{~m}$. Near to the border with Benin, some inselbergs occur reaching altitudes above $300 \mathrm{~m}$.

As shown in figure 3, Togo is located at the eastern edge of one of the four African cratons, which remained stable for almost 1,500 million years and since have little been disturbed. Near to the cratons, zones have been folded and faulted. The fold lines to the east of the West African craton are oriented in SW-NE direction. This can be illustrated in the appearance of the hydrographical network (Figure 4). The main rivers in the study area are the river Mono, river Ogou and river Ofé. The hydrographical network has a rectangular pattern with a dominant NNE-SSW direction, perpendicular to the direction of their tributaries.

The western fringe of the craton was subject to a tectonic subsidence; it has been filled up with sediments which altered into a granito-gneiss complex of Precambrian age (Dahomenian series). 


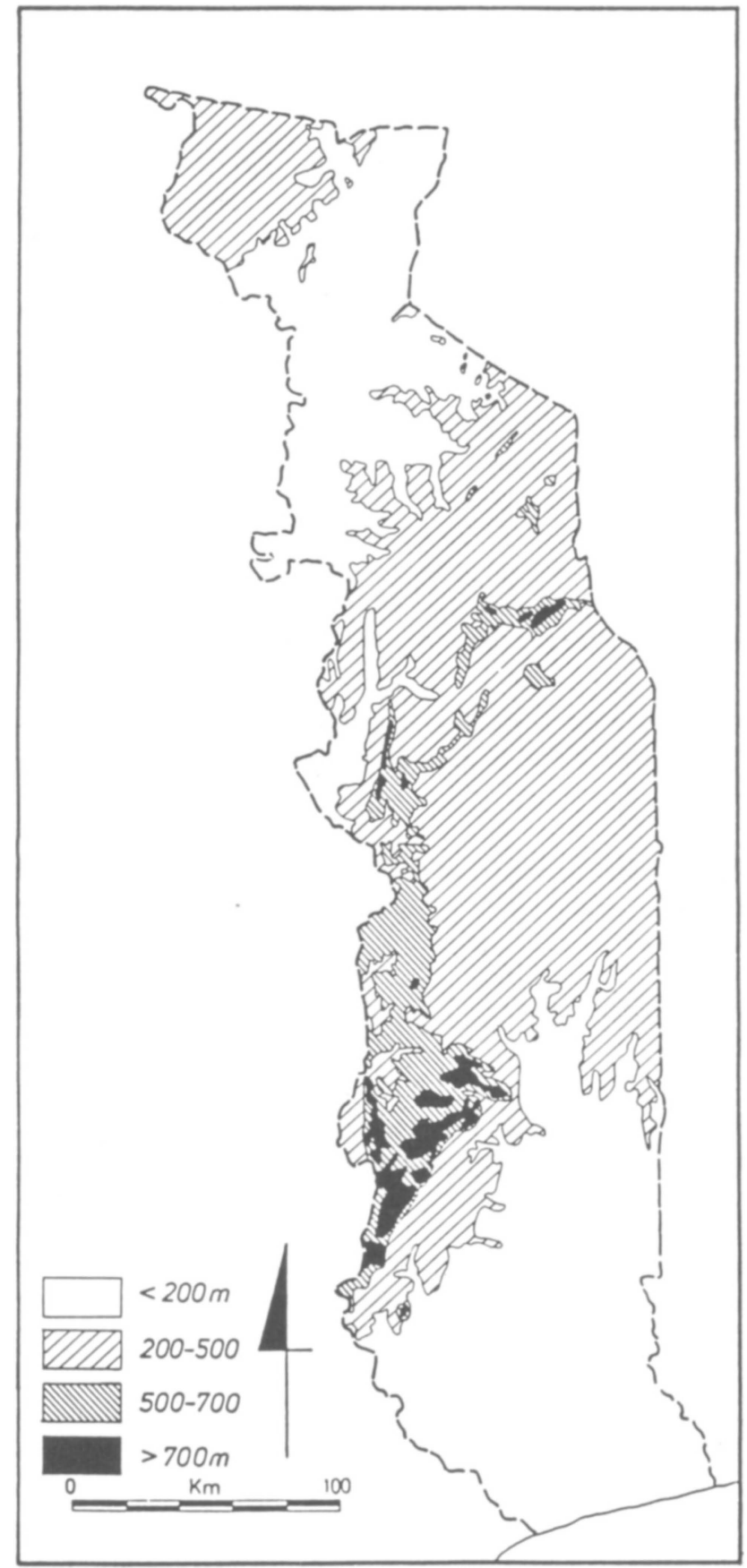

Figure 2 - Elevation map of Togo 


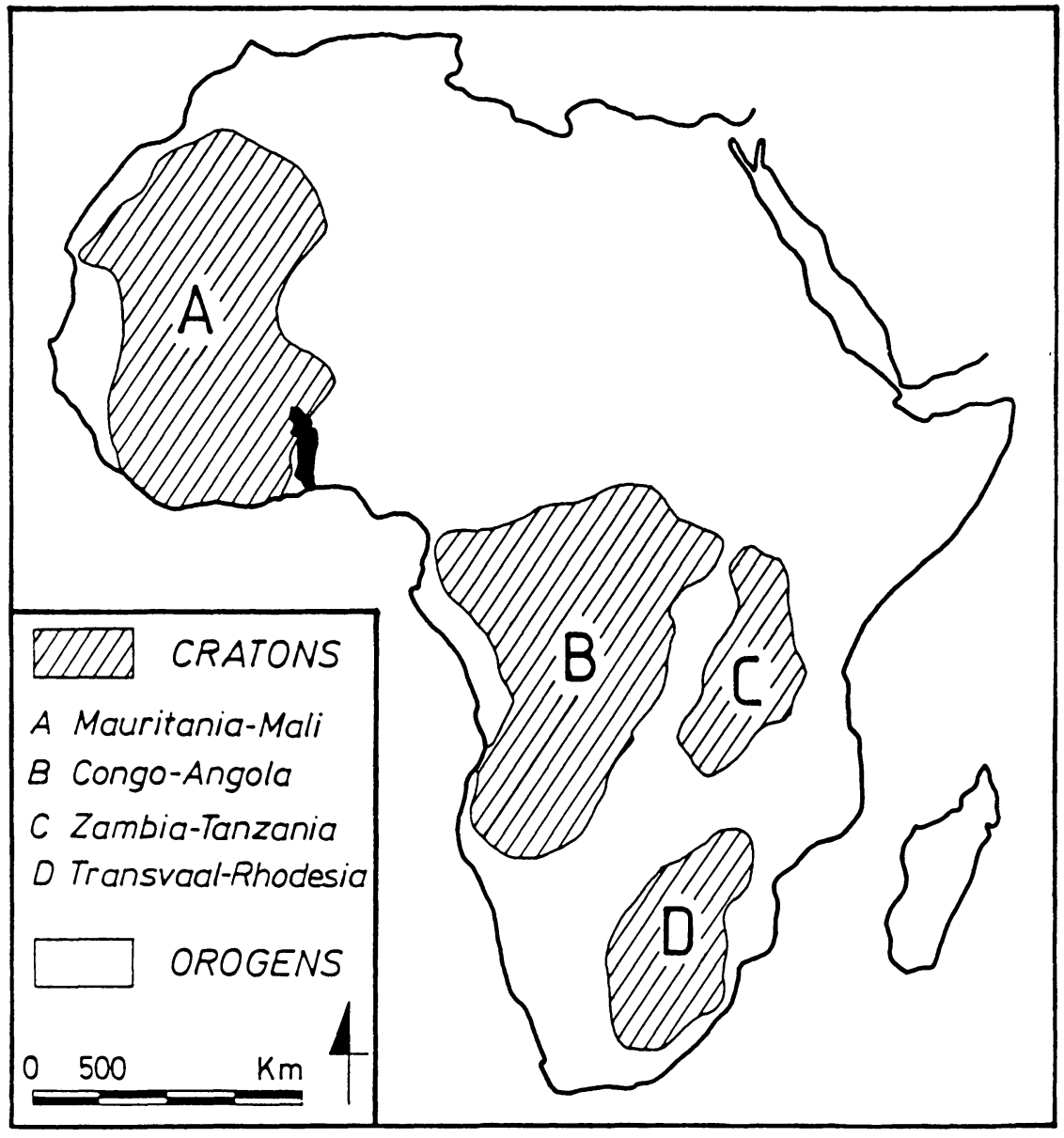

Figure 3 - Localization of the cratons in Africa (after GASS, I.G. et al. - 1972) 


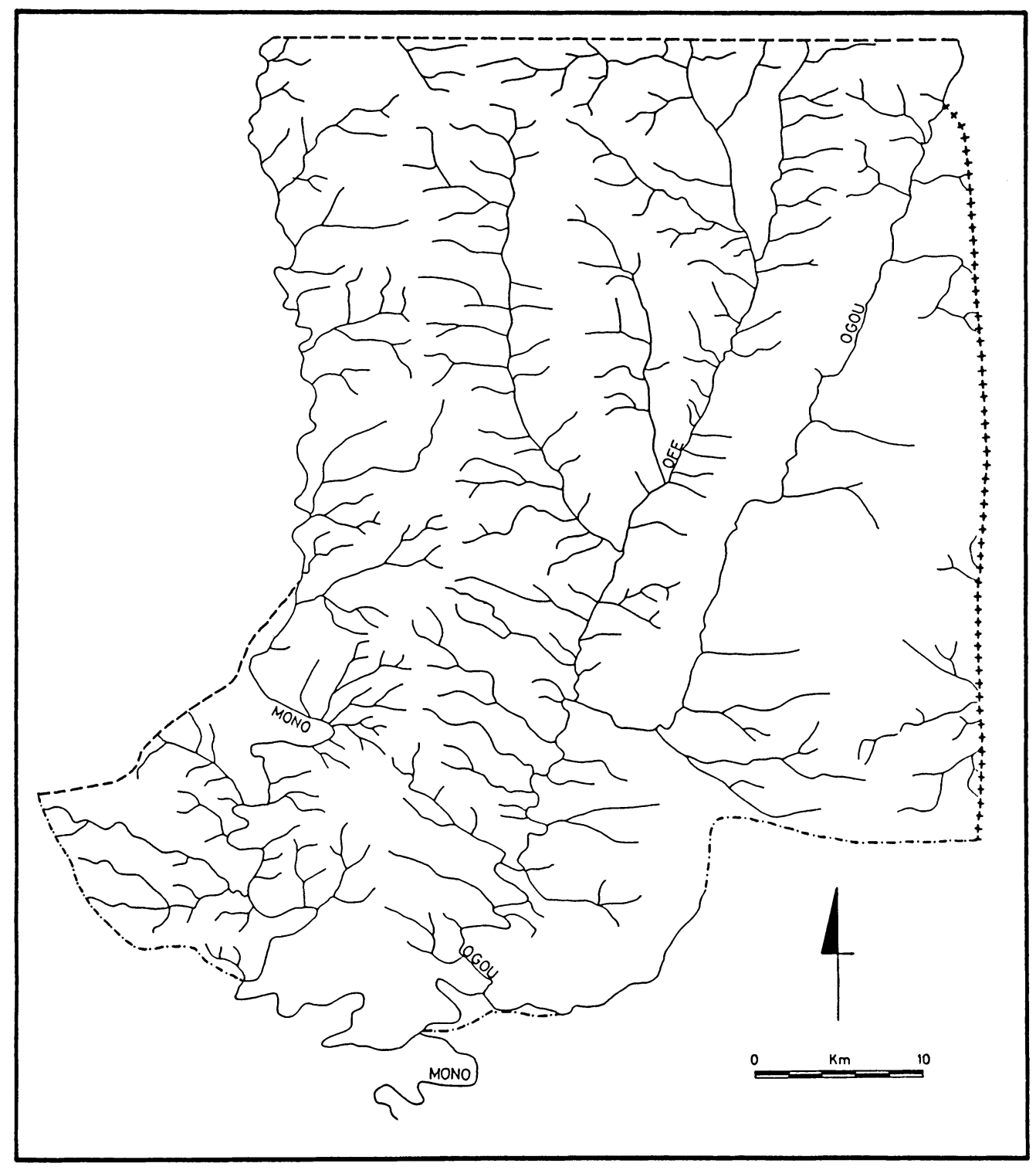

Figure 4 - Hydrographical map of East Mono Region (The dotted area represents part of the study region as found in figure 12 and figure 14) 


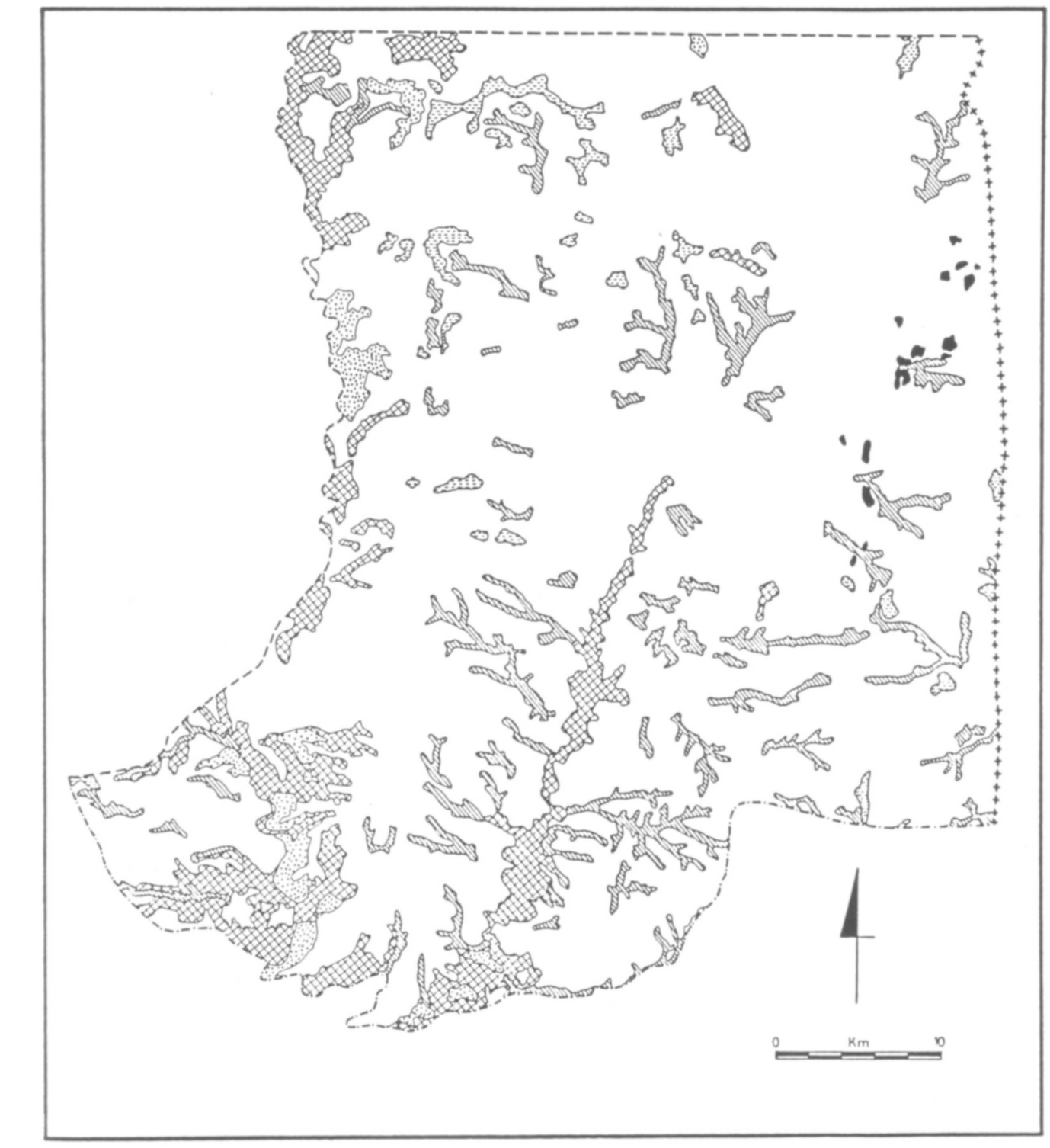

FERRUGINOUS SOILS

FERRALLITIC SOILS

VERTISOLS

HYDROMORPHIC SOILS

POORLY DEVELOPED SOILS

LITHOSOLS

Figure 5 - Generalized soil map of East Mono Region

(after LEVEQUE, A. - 1979) 
The climate of Togo is of two types. North of the $8^{\circ} \mathrm{N}$-latitude, the climate is of the Sudan type with one rainy season extending from March to the end of October, and one dry season. South of the $8^{\circ} \mathrm{N}$-latitude, the climate is of the Guinea type with two dry seasons (November-March and July-September) and two rainy seasons.

The study area is located at the transition between the two climatic types. The mean temperature shows only little variation during the year and varies between $23.5^{\circ} \mathrm{C}$ in August and $27.5^{\circ} \mathrm{C}$ in February. The mean annual rainfall amounts about 1,300 $\mathrm{mm}$. Strong variations, however, occur during the year as well as year by year for which ratios between minimum and maximum of $1 / 5$ were noted (LEVEQUE, 1979). In general, the climate of the study area is characterized by one dry and one rainy season. The dry season lasts from early November till mid April. The rainy season can be subdivided into two periods: a first, short moist period of about two to three weeks and the main rainy season starting mid May.

As illustrated in figure 5, most part of the study area is covered by ferrugineous soils. They are developed on the Precambrian granito-gneiss basement. These soils are of sandy clay loam texture and have a low water holding capacity.

Ferrallitic soils, characterized by an intensive leaching, occur only in restricted parts of the study area. The texture is more or less uniform throughout the soil profile and is sandy clay.

Vertisols are mainly related to the river Mono. They are recently developed, at the lower part of the hill slopes. The texture is clay, with $45 \%$ fine particles in the upper horizon and gradually increasing to $60-70 \%$ in the lower part of the profile. The Vertisols are not used for the traditional agriculture because of their hostile physical characteristics: when too dry, it is not possible to use agricultural tools, and when the soil is too wet, the stickiness is too high. Other soil types related to the hydrographical network are the poorly developed soils and the hydromorphic soils.

Lithosols are found in the eastern part of the study area at the height of the inselbergs, near to the border with Benin. These soils are developed on gneiss and granites and mainly occur as rock outcrops of the parent rock. They are characterized by a high rate of runoff. Concentric around the Lithosols, lithic soils and tropical Rankers, characterized by an accumulation of organic material and gravels of the parent rock, occur. At the foothills, poorly developed soils on quartz-sandy material are found.

Togo is located at the transition between the semi-deciduous, dense forest and the typical savannah and is characterized by a heterogeneous vegetation cover. The 
variation in vegetation types is due to differences in palaeo and actual climate, soil and human impact (LEVEQUE, 1979).

Most part of Togo is covered with a woodland- or shrub savannah of which the density of the crown cover is highly variable. The semi-deciduous forest only occurs in the southwestern part where climate is favourable (more than $1,250 \mathrm{~mm}$ of annual rainfall and less than three consecutive dry months).

Two types of tree vegetation occur in the study area, namely: the gallery forests and the open woodland. Gallery forests have an homogeneous aspect; they are located along the main axes of the drainage system. The open woodland is deciduous; it is characterized by a rather dense crown cover and a discontinuous cover of herbs and grasses. Vast areas are covered with an open woodland vegetation, mainly along the drainage interfluvia and on the hill slopes.

The grassland savannah is found in the zones where, due to the abundant savannah fires, a vegetation of trees and shrubs is no longer possible.

The shrub savannah and the woodland savannah have identical characteristics. The difference, however, is caused by the human impact resulting in a vegetation degradation. Shrub savannah is found on poor soils or soils with a pan-horizon.

The woodland savannah is an open and discontinuous vegetation type. The ground cover of grasses, in general higher than $80 \mathrm{~cm}$, is very dense. This is the main vegetation type of the land of Togo. In the study region, woodland savannah only occurs in limited zones on the plateau near the border with Benin.

It is difficult to make a clear distinction between the natural vegetation and the land use. The agriculture is of the type of shifting cultivation. Most soils would become exhausted under the prevailing climate when cultivated and in the case that fallow would not be applied. The fallow period takes up to eight years. The main crops, cultivated during two or three consecutive years, are: during the first year cotton, during the second, and eventually third year, food crops (sorghum and maize).

The growing period of cotton takes four to five months. Cotton is planted by the end of May, early June and gathered by the onset of the dry season. Maize has a growing period of 120 days and is planted during the month of April. Because of its higher tolerance of drought, sorghum is sown in the midst of May. 


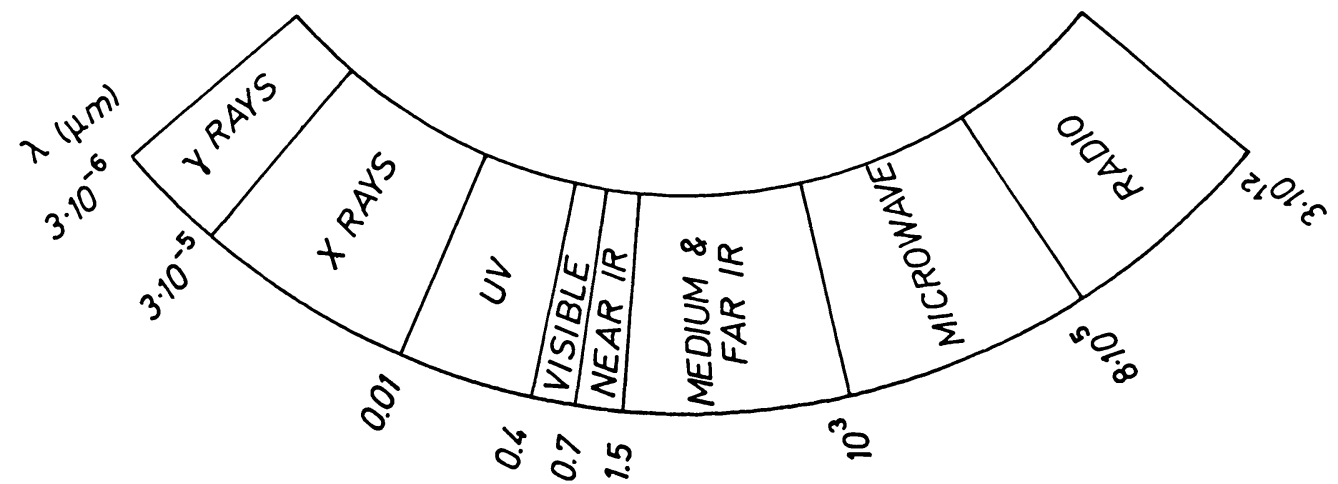

Figure 6 - The electromagnetic spectrum
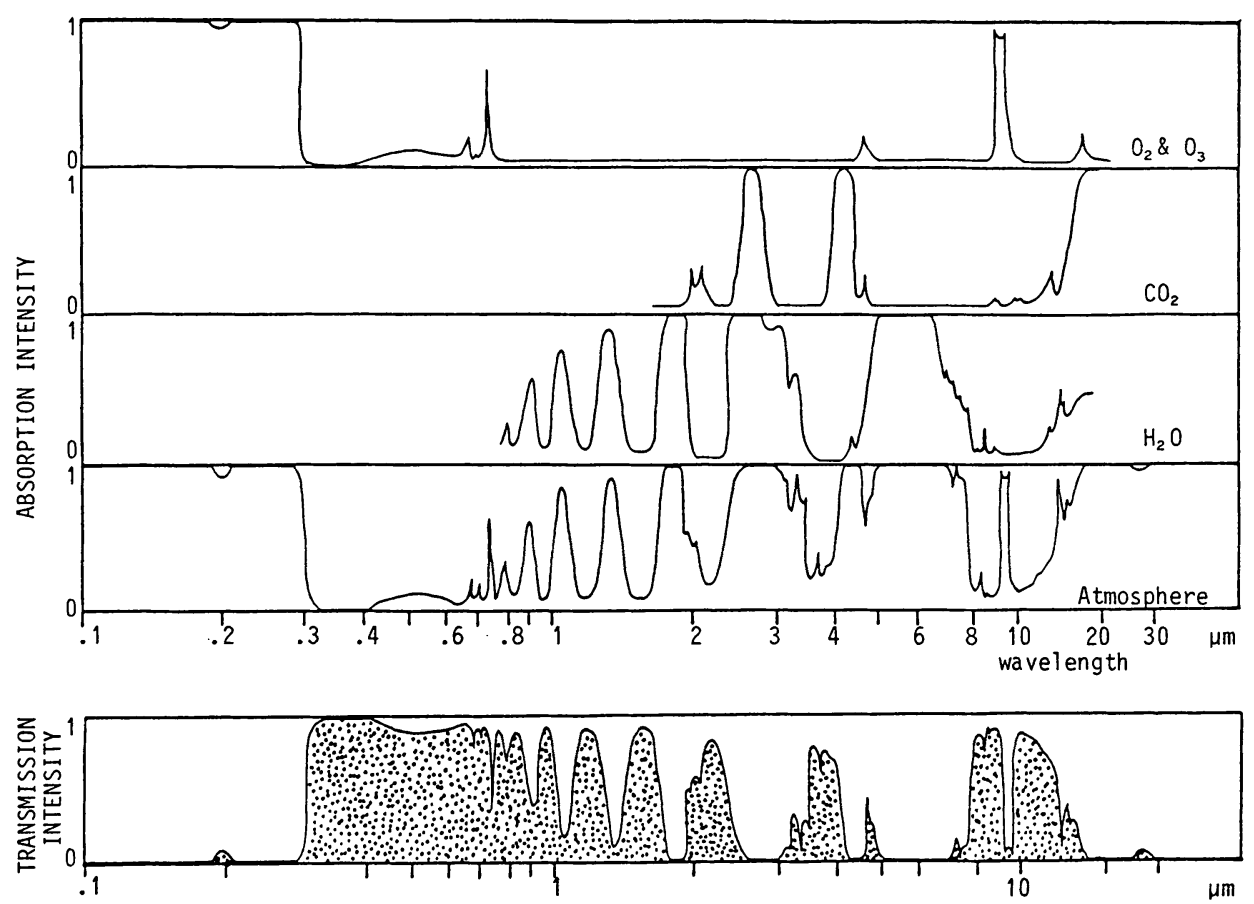

Figure 7 - Influence of the atmosphere and its components on the composition of the incident light (after BARRETT, E.C. \& CURTIS, L.F. - 1978) 
Teak plantations are found along the roads and in the neighbourhood of villages. The plantation have in general an areal extend of $50-100 \mathrm{~m}$ by $100 \mathrm{~m}$, and the trees are planted at a distance of six to seven $m$.

\section{BASIC CONCEPTS OF REMOTE SENSING}

\subsection{Introduction to remote sensing}

With regard to the nature of the energy used, two types of remote sensing systems can be distinguished, which are:

- the active systems which supply their own source of energy or illumination, e.g. radar, and

- the passive systems which sense radiation of a natural source such as the sun.

\subsubsection{The sun as a radiation source}

The sun is the most important radiation source for remote sensing. She emits electromagnetic radiation mainly in between 0.01 and $100 \mu \mathrm{m}\left(1 \mu \mathrm{m}=10^{-6} \mathrm{~m}\right)$, thus ultraviolet, visible (blue, green, red), near infrared, medium and thermal infrared light (Figure 6). The maximal radiation intensity is reached for the blue and the green visible light.

\subsubsection{The interaction with the atmosphere}

All radiation passes through the atmosphere. The atmosphere strongly influences the intensity and the spectral composition of the radiation. This is mainly due to the atmospheric absorption and the scattering of the light.

\section{The atmospheric absorption}

An important part of the solar radiation is absorbed when passing the atmosphere. This results in a loss of energy which is transmitted to various atmospheric components: oxygen, ozone, carbon dioxide and water (Figure 7). Water is the most important absorbing agent. It absorbs light between 0.7 and $8 \mu \mathrm{m}$, with a maximal intensity at $6.9 \mathrm{~m}$. As shown in figure 7, only distinct parts of the electromagnetic spectrum are absorbed by the atmospheric components. Thus, certain intervals of the 


\begin{tabular}{|llc|}
\hline Earth & Surface Phenomenon & Albedo (\%) \\
\hline \multirow{2}{*}{ Soils : } & white, fine sand & 37 \\
& black, dry soil & 14 \\
& black, moist soil & 8 \\
Snow & & $86-95$ \\
Vegetation : Shrubs (deserts) & $20-29$ \\
& Deciduous trees & 18 \\
& Evergreen trees & 14 \\
\hline
\end{tabular}

Table 1 
incident light will be transmitted through the atmosphere. These intervals are called "the atmospheric windows". When using SPOT remote sensing data, the most important windows are:

- the UV and visible light: $0.30-0.75 \mu \mathrm{m}$, and

- near Infrared: 0.77-0.91 $\mu \mathrm{m}$.

\section{The atmospheric scattering}

All particles which are present in the atmosphere scatter the incident light. Depending on the size of the particles, three types of scattering can be distinguished:

- the Rayleigh scattering caused by molecules mainly affecting the ultraviolet and visible light,

- the Mie scattering caused by particles with a diameter of the same order as the wavelength of the radiation (water, dust), and

- the non-selective scattering caused by particles of which the diameter is much larger than the wavelength (clouds, smoke, fog). It scatters all visible and reflected infrared light.

\subsubsection{The interaction with the earth surface phenomena}

Once the atmosphere is passed, an interaction takes place between the incident light and the earth surface phenomena. This interaction comprises the absorption and the reflection of the light and is different according to the nature of the object, the surface roughness and the orientation of the object towards the incident radiation.

The reflection characteristics of objects are expressed in terms of "albedo" which is defined as the percentage of incident light that is reflected. Table 1 illustrates the albedo of some earth surface phenomena.

Different earth surface phenomena do not only reflect different amounts of incident light, but also differences in reflection are noted according to the wavelength. This is defined as the "spectral signature" of an object which is one of the basic concepts 
in remote sensing. Figure 8 illustrates the spectral signature of water, vegetation and bare soil.

This figure shows that water strongly absorbs all incident light. The amount of light reflected by the soil increases with increasing wavelength. Depending on the soil humidity, however, the reflection of the light is different: the more humid the soil is, the more incident light will be absorbed. The spectral signature of vegetation is characterized by an absorption of the light at wavelengths essential for the photosynthesis, namely the blue $(0.4-0.5 \mu \mathrm{m})$ and red $(0.6-0.7 \mu \mathrm{m})$ light which are largely absorbed by the chloroplasts. This absorption is caused by the presence of pigments, such as chlorophyll a and b, carotenoids (caroteen and xanthophyll). The chloroplasts moderately reflect the green light $(0.5-0.6 \mu \mathrm{m})$ and the near infrared light $(>0.8 \mu \mathrm{m})$ remained unaffected by the chloroplasts and is highly reflected by the spongy mesophyl.

\subsection{Remote sensing by means of the SPOT-satellite}

The detection of the reflected light can be done, among others, by an unmanned satellite with the aim to view the earth surface in a systematical and repetitive way.

\subsubsection{General information concerning SPOT}

The program SPOT or "Satellite Pour l'Observation de la Terre" was started early 1978. Up to now, two satellites have been launched in French Guyana, namely:

SPOT-1 on February 21, 1986, and

SPOT-2 on January 22, 1990.

The SPOT satellites were launched in a circular, near-polar and sun synchronous orbit which has an altitude of $832 \mathrm{~km}$. The satellite SPOT moves from the north towards the south. Due to the sun synchronous aspect of its orbit, the SPOT-satellite descends across the equator at 10.30 AM local solar time. One revolution around the earth takes 101.4 ' to the effect of $14+5 / 26$ revolutions per day. Two consecutive tracks at the equator are at a distance of $2823.6 \mathrm{~km}$. The orbital cycle takes 26 days and comprises 369 revolutions. The reference tracks are $108.6 \mathrm{~km}$ apart at the equator and $54.3 \mathrm{~km}$ at $60^{\circ}$ latitudes. 


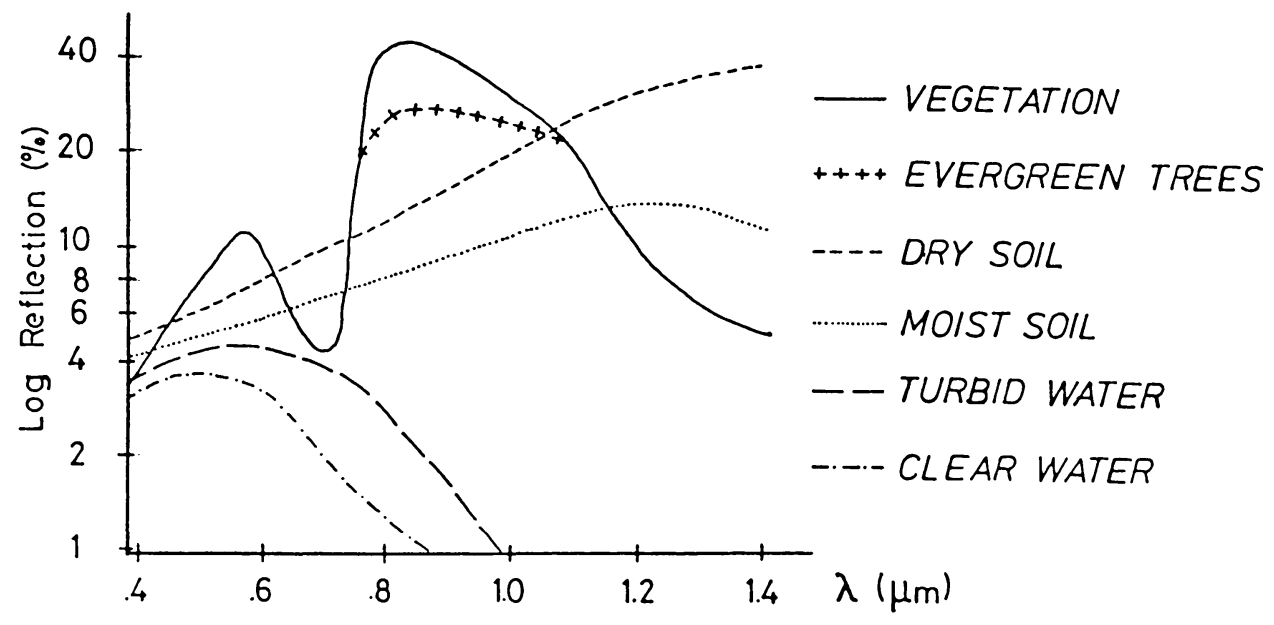

Figure 8 - Spectral signatures of some features (after JUSTICE, C.O.\& TOWNSHEND, J.R.G. - 1981) 

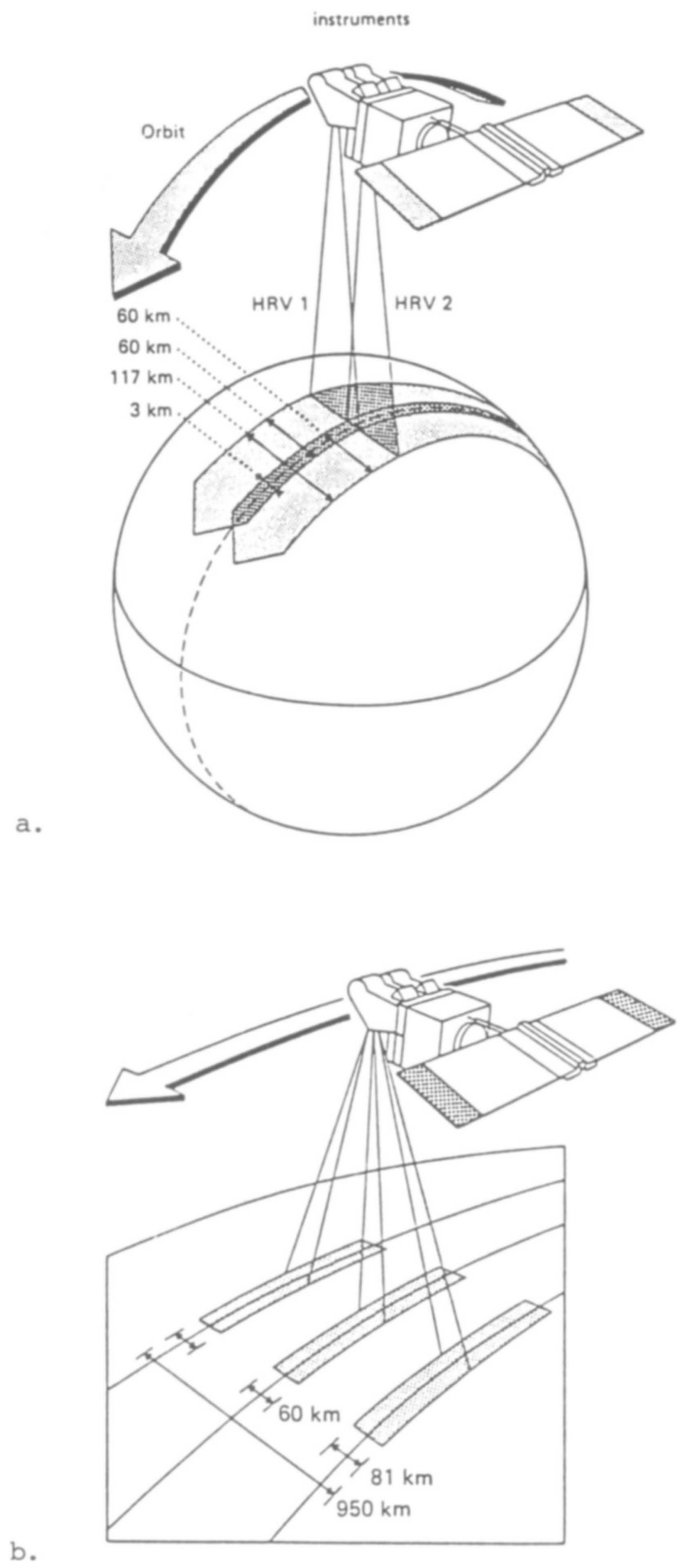

Figure 9 - SPOT-1 ground tracks

a. Nadir viewing, b. Off-nadir viewing

(CNES \& SPOT, 1986) 


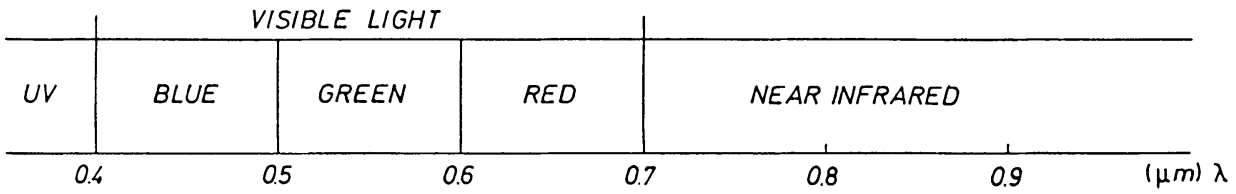

Multispectral mode

band 1, band 2

band 3

Panchromatic mode

Figure 10 - Spectral range of the SPOT satellite 


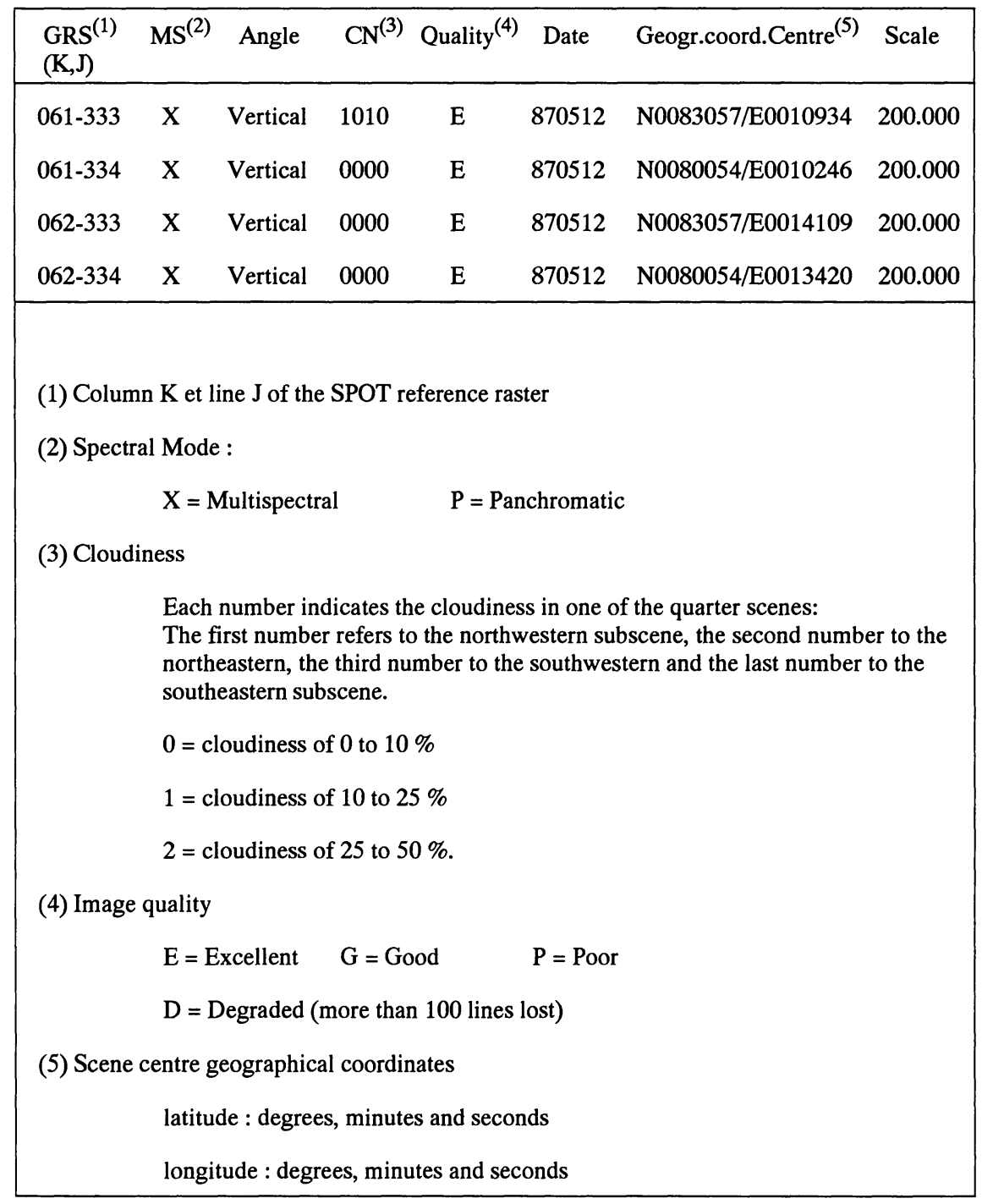

Table 2 


\subsubsection{Sensors on board SPOT-1}

The payload of SPOT-1 consists of two high resolution visible (HRV) imaging instruments, a package of two magnetic tape data recorders and a data-transmitter.

The imaging can be performed in two ways: nadir viewing, and off-nadir viewing (Figure 9). In the case of nadir viewing, the two HRV instruments are pointed in order to cover adjacent fields. The swath width of each scanning system is $60 \mathrm{~km}$, resulting in a total width of $117 \mathrm{~km}$ with an overlap of $3 \mathrm{~km}$. In the case of off-nadir viewing, it is possible to view any region of interest within a range of $950 \mathrm{~km}$ centred along the ground track. The swath width varies between $60 \mathrm{~km}$ and $81 \mathrm{~km}$. The advantage of off-nadir viewing is twofold: firstly, the number of observations can be increased in addition to the revisit frequency of 26 days, and secondly, due to the differences in viewing angle, it is possible to perform a stereoscopic analysis of the satellite images.

The high resolution viewing system can operate in two modes, namely (Figure 10):

- the panchromatic mode, corresponding to the spectral band $0.51-0.73 \mu \mathrm{m}$, and

- the multispectral mode, for which the observation of the earth is performed in three spectral bands:

band 1: green light: $\quad 0.50-0.59 \mu \mathrm{m}$

band 2: red light: $\quad 0.61-0.68 \mu \mathrm{m}$

band 3 : infrared light: $\quad 0.79-0.89 \mu \mathrm{m}$.

For nadir viewing, the instant field of view (IFOV) or ground element is $10 \times 10 \mathrm{~m}$ in the panchromatic mode and $20 \times 20 \mathrm{~m}$ in the multispectral mode. In the case of off-nadir viewing, the IFOV varies respectively between 10 to $13.5 \mathrm{~m}$ and 20 to $27 \mathrm{~m}$.

\section{METHODOLOGY}

\subsection{Image enhancement}

Four images covering the zone of interest, were to our disposal for analysis and mapping of the land cover. The characteristics of the images are given in table 2. As indicated in table 2, all images are recorded on May 12th 1987. Keeping in mind the climatic characteristics of the study region $(\S 2)$, the images are taken at the onset of 


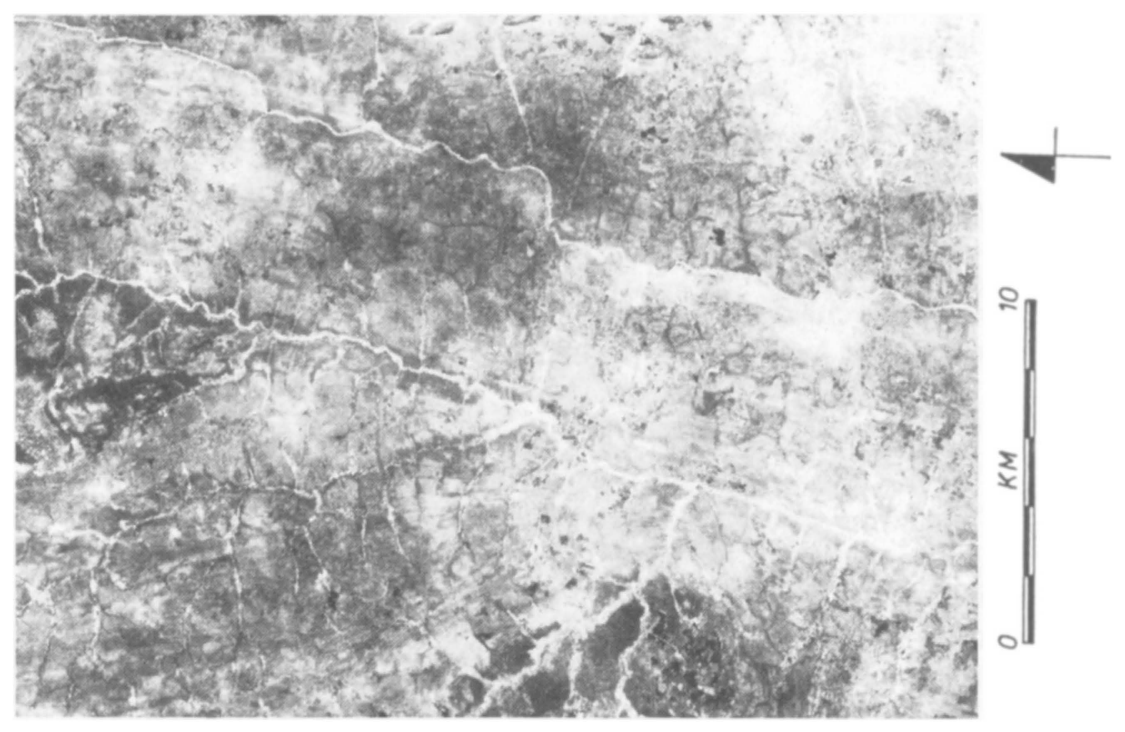


Figure 11 - Extract of a positive band 3 - image (scene: 062-334, date: 12.05.1987) c SPOT-image, 1987

(Localization of the area, see figure 4) 
the main rainy season. All images were available as black and white $(B \& W)$ negative transparencies rendered into positives using photographic film material characterized by a low contrast.

Figure 11 is a positive print of SPOT-band 3, indicating the reflectance of the infrared light. White zones highly reflect incident light and dark ones absorb the infrared light!

The use of $\mathrm{B} \& \mathrm{~W}$ satellite images as a basic document for cartographic purposes requires the enhancement of the original images. The enhancement technique applied, namely the diazo processing, transforms the image data into a more appropriate form for analysis.

The diazo processing is an inexpensive technique through which grey band levels are transferred into colour levels. The combination of the different colour levels will result in a multi-coloured image. The diazo technique is based upon the decomposition of diazonium salts which are sensitive to the light, in casu ultraviolet light $(0.36-0.44 \mathrm{~m})$. Once exposed, the diazo film is developed in an alkali environment by using ammonia vapour.

The satellite image is placed on top of the diazo film and arranged in a copy frame. After exposure, non decomposed diazonium salts remain at the non exposed regions of the film and under the influence of ammonia, the azo-component will form an azo-colour. The intensity of the colour depends on the grey level of the satellite image: the lighter the grey level, the more ultraviolet light will be transmitted and thus the lighter will be the azo-colour.

The procedure followed is illustrated in figure 12. The three spectral bands are rendered in yellow, magenta and cyan respectively, using:

TECHNIFAX
DIAZOCHROME
KYL-P KCY-P
Colour film
Yellow image Magenta image Cyan image
Ammonia development
4 mil clear polyester
The time of exposure and of development is given in table 3.

After exposure and development, the three coloured images are mounted on top of each other in order to make a false colour composite at scale 1/200,000. 


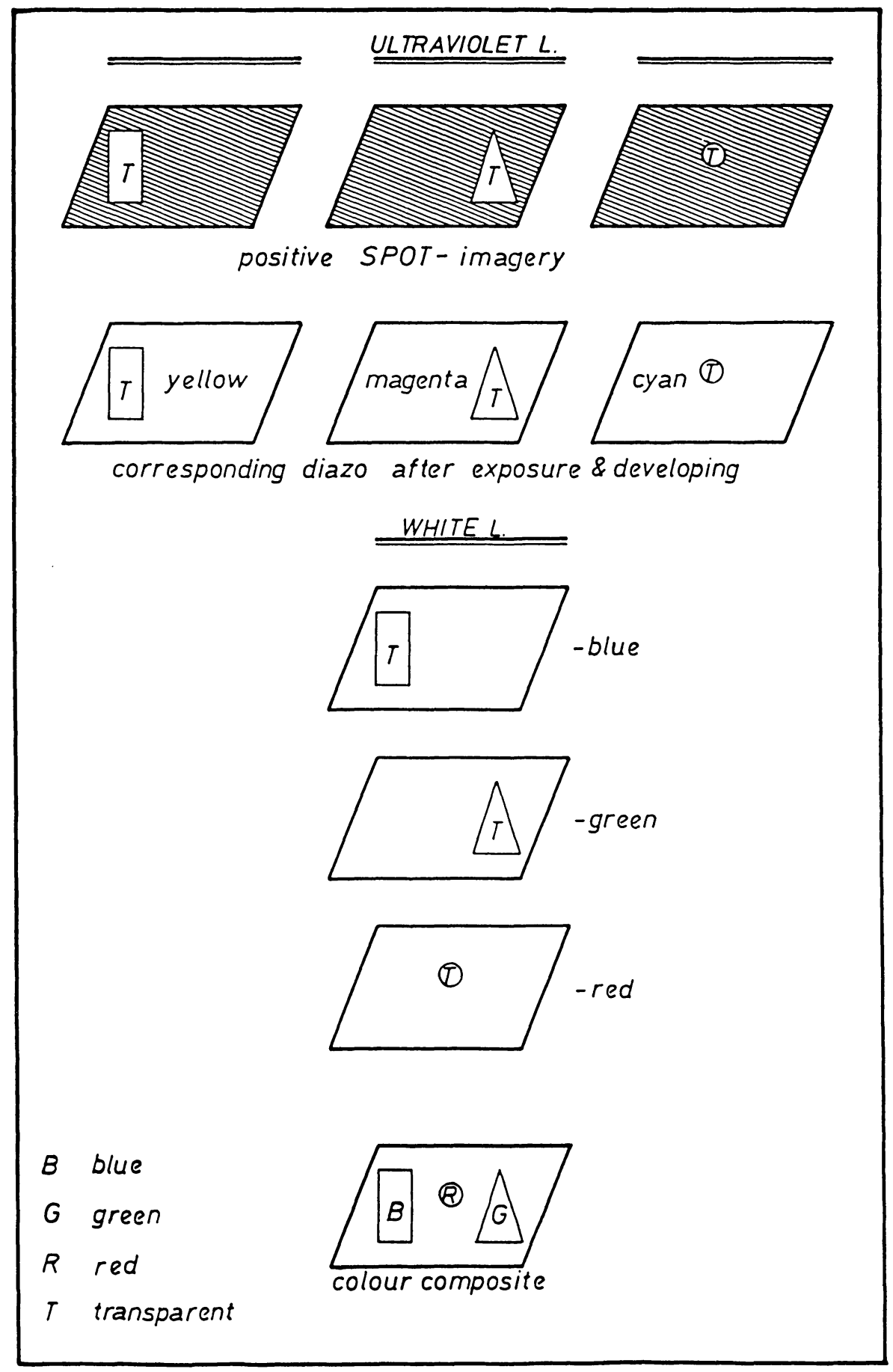

Figure 12 - Diazo technique 


\begin{tabular}{|llll|}
\hline & & UV & Ammonia \\
\hline Band 1+ & Yellow & $20^{\prime}$ & $3{ }^{\prime} 30^{\prime \prime}$ \\
Band 2+ & Magenta & $11^{\prime}$ & $10^{\prime \prime}$ \\
Band 3+ & Cyan & $10^{\prime}$ & $18^{\prime}$ after 30' heating of ammonia \\
\hline
\end{tabular}

Table 3 
Taken into consideration the spectral signatures of the objects (Figure 8 ) and the diazo colours used for the three spectral bands, it can be said that:

- the reddish colours refer to surface phenomena reflecting the infrared light: vegetation,

- the bluish colours refer to surface phenomena reflecting the red light and absorbing the infrared light: soils with a low vegetative cover,

- the pale colours refer to surface phenomena highly reflecting all incident light: f.i. sandy soils,

- the dark colours refer to surface phenomena absorbing all incident light: such as water and burned areas.

\subsection{Visual image interpretation}

The visual image interpretation can be subdivided into three different stages, namely: the analysis, the identification and the interpretation. The analysis and the interpretation of the colour composite has been performed at a scale 1/50,000 using an overhead projector.

\subsubsection{Image analysis}

This stage consists of the delineation of photomorphic units as described by COLE \& KING (1968) and DAELS \& ANTROP (1977). The major criteria for the image analysis are tonality (or colour) and texture, defined as differences in colour or tonality too small to be clearly discerned individually.

More precisely, the delineation of the photomorphic units is based upon:

- the dominant colour

- the colour of the textural elements

- the shape and the size of the textural elements, and

- the homogeneous aspect of the photomorphic unit. 
Four types of textural elements are distinguished:

1. Points having a diameter smaller than $1 \mathrm{~mm}$,

2. Patches and blocks with a diameter greater than $1 \mathrm{~mm}$. Patches and blocks differ in shape: blocks are geometrical and patches have an irregular shape, and

3. Lines which are much longer than their width.

In addition to the shape and the size of the textural elements, the photomorphic units have also been delineated based upon the distribution of the textural elements within the photomorphic units. Four distribution possibilities occur: random-homogeneous, random-heterogeneous, clustered-homogeneous, and clustered-heterogeneous.

The delineation of the photomorphic units resulted in a photomorphic unit map which is used as basic document for further image identification and interpretation.

\subsubsection{Identification}

This stage of the visual image interpretation consists of the collection of available information, such as: maps (topographical, pedological,...), ground truth.

Terrain data were gathered along transects by Dr. W. VERHEYE, Laboratory for General Pedology, and were mainly taken in function of the soil mapping. Data for 116 observations were available, including: topographical position, land cover type and crop type.

In addition, the photomorphic characteristics of the reference points were noted based upon the false colour composite and translated in terms of the spectral signature of the vegetative cover.

\subsubsection{Interpretation}

The interpretation of the image analysis consists of the extrapolation of results obtained for the reference points to regions for which no data are available. For this, a decision tree is set up including the main characteristics of the photomorphic units and converted into a specific land cover type (Figure 13). 


\section{Photomorphic units}

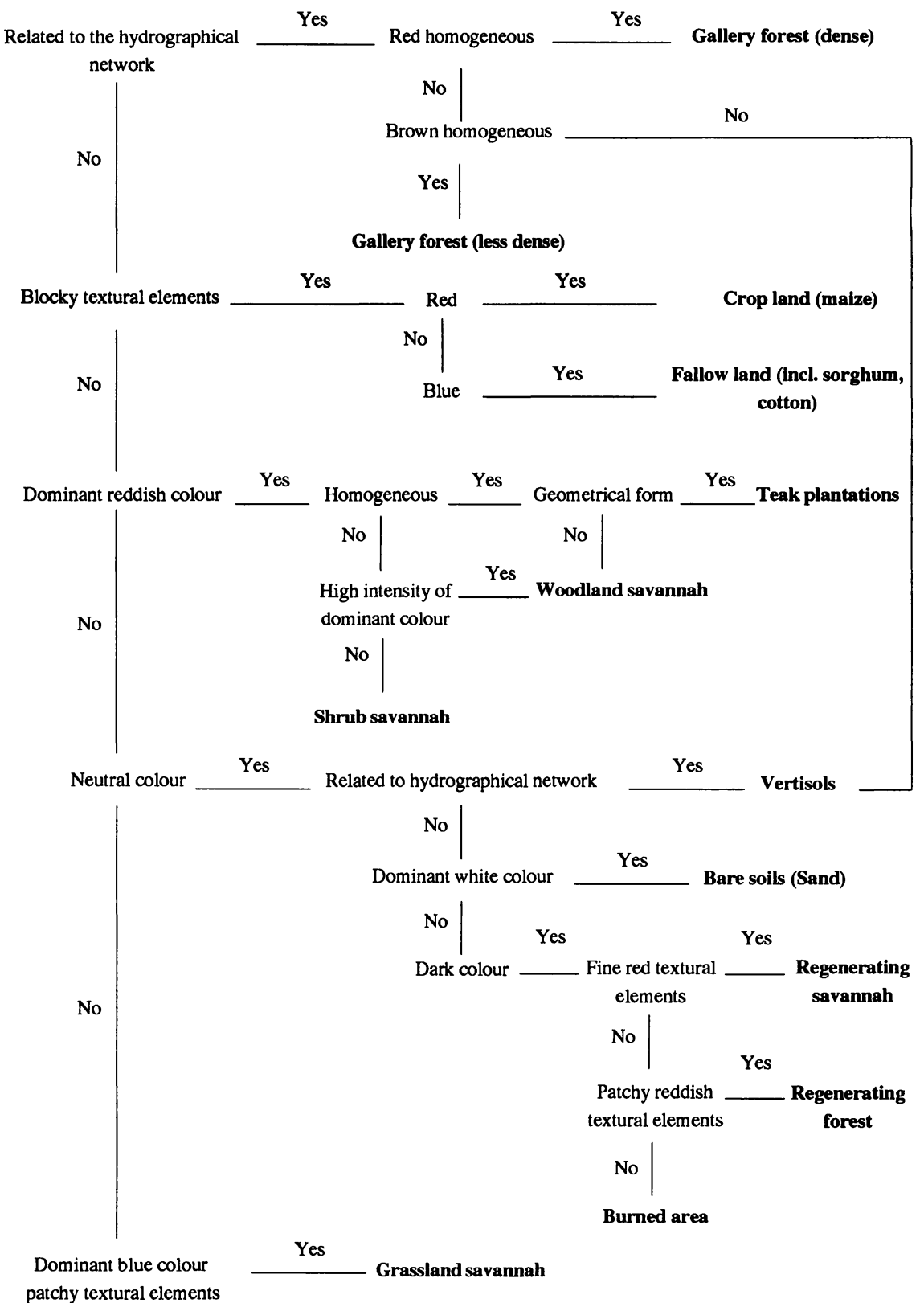

Figure 13 - Decision tree for the land cover mapping 

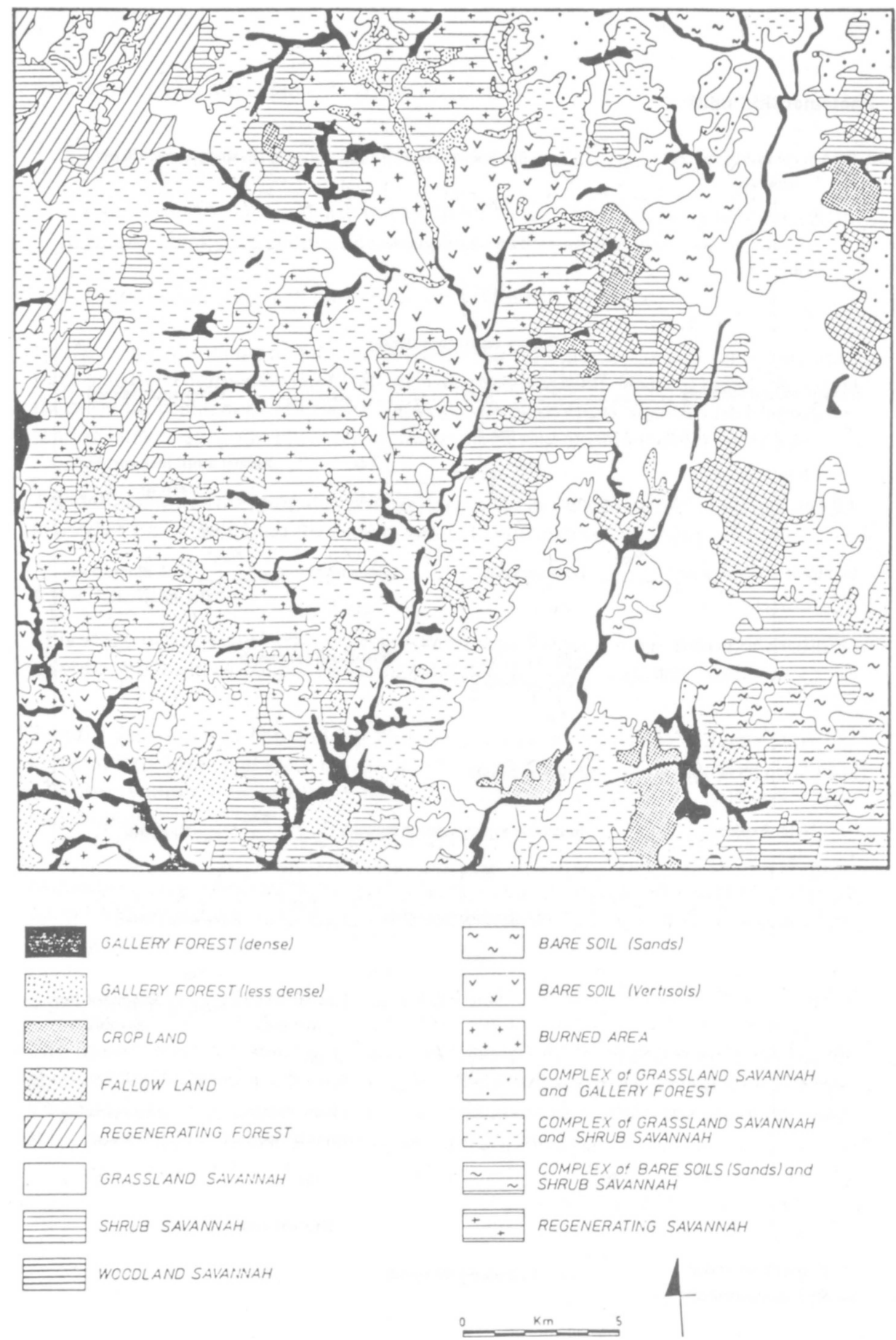

Figure 14 - Extract of the land cover map (Localization of the area, see figure 4) 


\subsection{Quantification}

The quantification of the different land cover types has been performed in raster format. A reference grid of $5 \mathrm{~mm}$ at scale $1 / 50,000$ corresponding to a ground distance of $250 \mathrm{~m}$, is used.

\section{RESULTS AND DISCUSSION}

The visual interpretation resulted in a land cover map distinguishing six main vegetation and land cover types: 1 . Gallery forests, 2 . Cultivated land, 3. Fallow land, 4. Savannah, 5. Burned area and 6. Bare soils.

Due to the occurrence of subtypes and of complex vegetation types, the land cover map (Figure 14) includes sixteen different classes: 1 . Gallery forests with a dense vegetative cover, 2 . Gallery forests with a less dense vegetative cover, 3. Crop land, 4. Fallow land, 5. Grassland savannah, 6. Complex of grassland savannah and gallery forests, 7. Complex of grassland savannah and shrub savannah, 8. Shrub savannah, 9. Woodland savannah, 10. Regenerating savannah, 11. Bare soils (sands), 12. Bare soils (clays), 13. Burned areas, 14. Regenerating forest, 15. Complex of shrub savannah and bare sandy soils, and 16 . Teak plantations.

\subsection{Gallery forests}

By means of a visual image interpretation, two types of gallery forests can be distinguished: 1 . Gallery forests characterized by a homogeneous and very dense crown cover, and 2. Gallery forests with a less dense crown cover. Both types of gallery forests are limited to the main drainage systems.

Gallery forests of the first type are represented by photomorphic units with a homogeneous red colour. The red colour indicates the high reflection of the infrared light and the total absorption of the visual red light. The homogeneous aspect of the photomorphic units refers to the homogeneous composition of the vegetation.

Gallery forests of the second type are represented by photomorphic units with a dominant brown colour, and reddish textural elements. This is due to the heterogeneous composition and the less dense cover. 
Both types of gallery forests cover about $9.8 \%$ (9.6\% and $0.2 \%$ for the dense and the less dense gallery forest respectively) of the total area.

\subsection{Cultivated land}

The cultivated land comprises the agricultural land (crop land and fallow land) and the teak plantations.

An indication for agricultural activity is found in the presence of blocky textural elements. Depending upon the colour of these textural elements and taking into consideration the date of recording (May 12th), two main agricultural classes can be observed: crops (maize) and fallow land (including the bare land used for cotton and sorghum cultivation).

At the time of recording, the only crop on the field is maize which was planted early April. This results in a reddish colour of the blocky textural elements referring to the presence of photosynthetic active material which reflects the incident infrared light and absorbs the red light.

The bluish blocky textural elements, indicating an absorption of the infrared light, refer to the lands used for cotton and sorghum, as well as the abandoned land (fallow land).

The crop land and the fallow land respectively occupy $7.4 \%$ and $12.4 \%$ of the total area.

The regenerating forest corresponds to formerly abandoned agricultural land. It is characterized by a vegetation of shrubs and few trees, and relative open crown cover.

The regenerating forest is represented by photomorphic units with a dominant dark tonality and patchy reddish textural elements, referring to the former agricultural activity. This vegetation type occupies $1.8 \%$ of the total area and mainly occurs in the western part of the study region.

Teak plantations are represented on the false colour composite by homogeneous red photomorphic units with a geometrical boundary. They are located along the roads and in the neighbourhood of villages, mainly in the extreme south of the study area, near to Kolokopé. The plantations occupy only a restricted part $(0.2 \%)$ of the area. 


\subsection{Savannah}

Grassland savannah is represented by photomorphic units with a dominant bluish colour, referring to the absorption of the infrared light and the reflection of the visible red light. This spectral signature is characteristic for earth surface phenomena with a poor vegetation cover.

Grassland savannah is the main vegetation type of the study area: $25.7 \%$ of the study area, and even more because of the occurrence of complex classes: complex of grassland savannah and gallery forests $(4.9 \%)$, and complex of grassland savannah and shrub savannah $(9.6 \%)$.

The shrub savannah and woodland savannah are both represented by photomorphic units with a dominant reddish colour, because of the reflection of the incident infrared light, and the absorption of the red light. The two types can be distinguished based upon the intensity of the red colour. The brighter the colour, the higher will be the photosynthetic activity of the vegetation cover as it is the case for woodland savannah.

Shrub savannah mainly occurs on the plateaux near to the border with Benin, where woodland savannah only is present at restricted locations. Shrub savannah and woodland savannah respectively cover about $12.2 \%$ and $2.2 \%$ of the study area.

\subsection{Bare soils}

Two types of bare soils are distinguished, which are: sandy soils and clayey soils with vertic characteristics (Vertisols). Sandy soils are mainly found on the plateaux; Vertisols are limited to the river system and are hydromorphic.

As given in table 1, both soil types are characterized by a strongly different albedo. The albedo of sands amounts $37 \%$ of the incident light, compared to the one of hydromorphic (wet) soils which is only $8 \%$.

The main criterion for distinction between the two soil types is the dominant colour of the photomorphic unit. Sandy soils reflect the light in all spectral bands, opposite to the Vertisols which highly absorbs the incident light. This results in a white colour representing the sandy soils, and a dark colour referring to the Vertisols. Bare soils occur on $8 \%$ of the area, $5.8 \%$ and $2.3 \%$ for sands and clayey soils respectively. 


\subsection{Burned areas}

Forest fires are set on in order to accomplish the growth of new grasses on the savannah. They occur over vast areas having sharp boundaries and are often limited by gallery forests.

Zones of forest fires mainly are mapped along the rivers Ofe and Kaniame, in the northern part of the study region occupying $0.8 \%$ of the total area. These zones highly absorb all incident light and are represented by dark coloured photomorphic units.

As it is the case for burned areas, the regenerating savannah also occur along the river Ofé. These zones have previously been burned; at the time of recording, new grasses germinated and are growing.

The regenerating savannah is represented on the false colour composite by photomorphic units with a dominant dark colour and fine, reddish textural elements indicating the regeneration of the vegetative cover. It occupies $5.1 \%$ of the total area.

\section{CONCLUSIONS}

Data recorded by satellites of the second generation, such as SPOT, offer great possibilities for the mapping of the earth surface phenomena at a large scale, and relative low cost level. This is mainly due to the synoptic view of the satellite $(60 \times 60$ $\mathrm{km}$ ) and the high ground resolution of $20 \times 20 \mathrm{~m}$ for SPOT multispectral images. However, raw data are not useful for the analysis and the interpretation, and image enhancements are required.

The method of analysis applied, based upon the photomorphic units, allows a classification of the image with limited terrain knowledge. These field observations are correlated to the image characteristics (tonality, texture) and used for the extrapolation to non observed regions in order to map the complete region of interest.

This paper illustrated the results obtained for the mapping of the natural vegetation and land use in a wet and dry tropical region at a scale of $1 / 50,000$. The use of diazo-processed multispectral images and the application of a visual image interpretation allowed to delineate the regional boundaries of the vegetation and the mapping of six main land cover classes, resulting in a land cover map indicating sixteen different classes. The quantification of the different classes has been performed at 
raster format, using a reference grid, allowing to estimate the degree of land use (crop land and fallow). The cultivated land, however, includes two types of fallow: on the one hand, short term fallow land is found which stands for the bare land used for maize and cotton cultivation, and on the other hand, long term fallow lasting for seven to eight consecutive years. Based upon a monotemporal data set, it is not possible to differentiate between the two types since they both have identical spectral signatures and the use of multitemporal imagery for differentiation is essential.

\section{REFERENCES}

BARRETT, E.C. \& CURTIS, L.F. (1978). Introduction to environmental remote sensing, 336 p. London: Chapman and Hall.

CNES \& SPOT IMAGE (1986). Guide des utilisateurs de données SPOT. Volume 1: Manuel de référence. Toulouse: $\mathrm{CNES}$.

COLE, J. \& KING, C. (1968). Quantitative Geography, 692 p. London: J. Wiley.

DAELS, L. \& ANTROP, M. (1977). The extraction of soil information from remote sensing documents. Pedologie 27, 123-190.

GASS, I.G.; SMITH, P.J. \& WILSON, R.C.L. - eds. (1972). Understanding THE EARTH, 383 p. Sussex: the Artemis Press.

GRIFFITHS, J.F. - ed. (1972). World Survey of Climatology. Volume 10. Climates of Africa, 604 p. Amsterdam: Elsevier.

JUSTICE, C.O. \& TOWNSHEND, J.R.G. (1981). The use of Landsat data for land cover inventories of Mediterranean lands. In: Terrain analysis and remote sensing, 133-153. London: George Allen \& Unwin.

LEVEQUE, A. (1979). Carte pédologique du Togo à 1/200,000. Notice explicative nº $82,77 \mathrm{p}$. Paris: Orstom. 
LILLESAND, T.M. \& KIEFER, R.W. (1987). Remote sensing and image interpretation, 721 p. New York: J. Wiley.

LOCKWOOD, J.G. (1974). World climatology. An environmental approach, 330 p. London: E. Arnold.

VAN CHI-BONNARDEL, R. (1973). Grand atlas du continent Africain, 335 p. Paris: Ed. Jeune Afrique. 